\title{
Cardiac slowing and acute tryptophan depletion: a response to the letter of Hood et al.
}

\author{
Frederik M. van der Veen • Gabry W. Mies • \\ Maurits W. van der Molen • Elisabeth A. Evers
}

Received: 19 November 2008 / Accepted: 26 November 2008 / Published online: 10 December 2008

(C) The Author(s) 2008. This article is published with open access at Springerlink.com

With great interest, we have read the letter 'Cardiac slowing and acute tryptophan depletion: a comment on the paper by van der Veen et al.' by Hood et al. This letter is a comment on a recent paper by our group (van der Veen et al. 2008) describing the differential effects of acute tryptophan depletion (ATD) on cardiac and electro-cortical measures of performance monitoring. In the letter, the authors describe two specific cases in which ATD led to serious but transient cardiovascular side effects. These side effects involved significant episodes of bradycardia and in both cases, extra medical help had to be summoned. The authors present the cases as further evidence for an important role of serotonin in the cardiovascular system and underline the importance of cardiovascular screening of subjects participating in ATD procedures. We completely agree with the conclusions and think it is important to take note of the two described cases. However, we would like to stress that the important role of serotonin in cardiovascular regulation is well known (e.g., Jordan 2005; Dergacheva et al. 2007; Ramage and Villalon 2008) and was already briefly mentioned in our

\footnotetext{
F. M. van der Veen $(\bowtie) \cdot$ G. W. Mies

Department of Psychiatry, Erasmus Medical Centre,

Rotterdam, the Netherlands

e-mail: f.vanderveen@erasmusmc.nl

M. W. van der Molen

Department of Psychology,

University of Amsterdam,

Amsterdam, the Netherlands

E. A. Evers

Department of Psychiatry and Neuropsychology,

University of Maastricht,

Maastricht, the Netherlands
}

paper. Furthermore, the participants in our studies are always thoroughly screened for cardiovascular and other health problems. Finally, the described cases seem to be very atypical and that the cardiovascular side effects are most likely unrelated to the effects on heart rate in our study.

Both the described cases had cardiovascular abnormalities before the start of the experiment and perhaps more thorough screening might have led to exclusion of these two patients. Moreover, both cases were psychiatric patients with a history of medication use, which might have contributed to a pre-existing cardiovascular vulnerability. Besides the ATD manipulation, case 2 was also given an infusion of the benzodiazepine antagonist flumazenil, which might have further added to any pre-existing vulnerabilities. Therefore, we think that the described patients are not the typical volunteers who participate in ATD studies, and that a combination of factors might have added to the effects of ATD. In all the studies performed by our group, in which we have included thoroughly screened healthy volunteers with or without a family history of depression, we have never encountered cardiovascular side effects of our procedures. However, it should be noted that we have incidentally encountered physical side effects such as nausea and vomiting and that these side effects have led to incidental dropout.

The described cardiovascular side effects are most likely unrelated to the effects described in our study. There is strong evidence for a role of serotonin in the brain circuits involved in feedback processing (e.g., Cools et al. 2008; Jocham and Ullsperger 2009) and cardiac responses to feedback are highly sensitive to subtle changes in activation in these circuits (e.g., Crone et al. 2003; van der Veen et al. 2004). Therefore, we like to argue that the cardiac effects described in our paper are related to changes in these 
higher-order circuits. In our study, it was found that ATD attenuated the cardiac response to negative feedback, but did not affect the response to positive feedback. In other words, ATD did not affect heart rate itself, but selectively influenced the stimulus-related effect on heart rate. Therefore, we think that it is most unlikely that this effect is caused by peripheral changes or by influences on the lower brain structures mentioned by Hood et al. Such effects would have caused an undifferentiated effect of ATD and therefore, it is more likely that changed activation in the earlier-mentioned higher-order circuits is responsible for the described subtle changes in the phasic cardiac responses. Finally, in a second task that was performed by the same group of healthy volunteers we also found a differential effect of ATD on the cardiac response to congruent and incongruent flanker stimuli (van der Veen et al., submitted) which again pointed in the direction of the involvement of higher cortical areas.

Open Access This article is distributed under the terms of the Creative Commons Attribution Noncommercial License which permits any noncommercial use, distribution, and reproduction in any medium, provided the original author(s) and source are credited.

\section{References}

Cools R, Roberts AC, Robbins TW (2008) Serotoninergic regulation of emotional and behavioural control processes. Trends Cogn Sci $12: 31-40$

Crone EA, van der Veen FM, van der Molen MW, van Beek B (2003) Cardiac deceleration following meaningful negative feedback. Biological Psychology 64:151-165

Dergacheva O, Griffioen KJ, Wang X, Kamendi H, Gorini C, Mendelowitz D (2007) 5-HT(2) receptor subtypes mediate different long-term changes in GABAergic activity to parasympathetic cardiac vagal neurons in the nucleus ambiguus. Neuroscience 149:696-705

Jocham G, Ullsperger M (2009) Neuropharmacology of performance monitoring. Neurosci Biobehav Rev 33:48-60

Jordan D (2005) Vagal control of the heart: central serotonergic (5-HT) mechanisms. Exp Physiol 90:175-181

Ramage AG, Villalon CM (2008) 5-Hydroxytryptamine and cardiovascular regulation. Trends Pharmacol Sci 29:472-481

Van der Veen FM, Van der Molen MW, Crone EA, Jennings JR (2004) Phasic heart rate responses to performance feedback in a time production task: effects of information versus valence. Biological Psychology 65:147-161

Van der Veen FM, Mies GW, van der Molen MW, Evers EA (2008) Acute tryptophan depletion in healthy males attenuates phasic cardiac slowing but does not affect electro-cortical response to negative feedback. Psychopharmacology (Berl) 199:255-263 